\title{
Chapter 3 \\ Two Hours Earlier, Near the Ladskie Artificial Lake
}

\begin{abstract}
Aleksey Artemios knew the sound with a level of fear that traveled like blood through his veins. Strikes of lightning and the subsequent rapid thunder. Twelve years before, he'd been among the lucky ones to survive the Nyamiha disaster in Minsk when a freak storm terrified hundreds of people in one of the city's crowded metro stations. There was a stampede for cover, everyone slipping on the pavement, and more than fifty people were crushed to death in a tunnel.

Now, as he made his way back towards his encampment, he simply chose to wait it out under cover of a huge forest grove. The trees had formed a vast network of exposed roots, and some of the huge icicles had engendered a cave-like opening in which he took shelter. It offered a surprisingly high amount of heat.

His residual fear passed with the storm, and he now prided himself on his catch: several pounds of a certain fungus that only grew, as far as he knew, in this one small corner of the forest. His grandfather had discovered the area fifty years before, at great peril to himself and family, and since that time, the so-called "winter mushroom" had become all but inaccessible, if not nearly extinct in the wild.

Aleksey knew there were terrible risks, but he also now benefitted from something that would have been unimaginable to Aleksey's grandfather: it turned out that this particular fungus, which thrived under deep snow, contained certain chemicals, and a pharmaceutical company was happy to pay a fortune for whatever Aleksey could unearth.
\end{abstract}

It was a bonanza. In his wildest dreams he could never make such money from any normal activity.

As he resumed his trek back through the deep snow, he heard the one sound he had prayed he'd never have to worry about: barking dogs!

Perhaps they belonged to some other hunter, illegally doing his thing. That he could easily survive; he had in the past.

But then... His fate was sealed without question. They were Transylvanian hounds, the cries of their masters goading them on.

It was all over for him. He sat down beneath the nearest tree. 